\title{
A TEST FOR EFFICIENCY IN THE SUPPLY OF PUBLIC EDUCATION*
}

\author{
Theodore C. BERGSTROM \\ University of Michigan, Ann Arbor, MI 48109, USA \\ Judith A. ROBERTS \\ California State University, Long Beach, CA 90801, USA \\ Daniel L. RUBINFELD \\ University of California, Berkeley, CA 94720, USA \\ Perry SHAPIRO \\ University of California, Santa Barbara, CA 93106, USA \\ Received April 1986, revised version received April 1988
}

This paper devises and applies a statistical test for efficient provision of local public education. The test is based on the 'Samuelson condition' of equality between the sum of marginal rates of substitution and marginal cost. The econometric method is a micro-based approach to the estimation of the marginal rate of substitution function. This method accounts for possible 'Tiebout bias' caused by the fact that individuals may choose their school districts in accordance with their tastes for education.

\section{Introduction}

The question of whether governments spend too much or to little has been the subject of much debate but little econometric testing. This paper conducts an empirical test of whether local governments spend more or less than a Pareto optimal amount on local public goods. Our procedure is very simple in principle. We check whether the 'Samuelson first order conditions' [Samuelson (1954)] for efficient provision of public goods are satisfied. The Samuelson conditions require that the sum of individual marginal rates of substitution between a public good and the private numeraire equals the marginal cost of the public good. This condition is necessary for an interior Pareto optimum and in a well-behaved convex economy is also sufficient.

Theoretical arguments have been made which suggest that the amount of local public goods provided may be nearly efficient. Some of these arguments

\footnotetext{
*The authors are grateful for financial support from the National Science Foundation, the National Bureau of Economic Research, and the Center for Real Estate and Urban Economics (U.C. Berkeley).
} 
depend on the effectiveness of majority voting. Bowen (1943) proposed a model in which the amount spent on public goods is the median of the quantities desired by voter-taxpayers, where each voter realizes that in return for the benefits of additional public expenditure, he or she will have to bear a predetermined share of the extra cost. Bowen showed that if marginal rates of substitution are symmetrically distributed and public goods are paid for by a uniform 'head tax', then majority rule leads to a Pareto efficient supply of public goods. Bergstrom (1979) extended the Bowen efficiency theorem to include some cases where wealth is not symmetrically distributed and where there is a proportional wealth tax. Ledyard (1983) presented a model in which voters make rational decisions about whether to vote, candidates choose their positions strategically and political equilibrium is efficient. A different theoretical case for the efficiency of local public goods supply was inspired by the work of Tiebout (1956). Tiebout suggested that the competitive forces engendered by people 'voting with their feet' might lead to approximate efficiency. Similarly, Brueckner (1982) argues that community maximization of property values leads to efficiency. This line of argument is ably summarized and criticized by Bewley (1981) and Stiglitz (1983).

There is an interesting literature that argues that local public goods are undersupplied. Barlow (1970) suggested that the Bowen conditions are typically not satisfied and offered evidence that in the case of local school expenditures in Michigan, the median quantity demanded is less than the Pareto optimal amount. Some economists believe that voters systematically underestimate the benefits of public goods. Galbraith (1958) attributed this to the effect of private advertising. Downs (1960) argued that because information is costly and a single voter has a negligible effect on public outcomes, it is rational for voters to be less than fully informed about the effect of public goods. This, Downs argues, leads to a systematic underestimation of benefits, which are poorly understood, relative to tax costs which are easily understood. Some writers have suggested that local governments supply too little public goods because there are 'spillovers' in benefits from one city to another. These effects were analyzed by Brazer (1961), Weisbrod (1964), and Williams (1966).

Others have made appealing arguments that 'too much' is spent. Romer and Rosenthal (1978), Brennan and Buchanan (1977) and Denzau, MacKay and Weaver (1981) argue that bureaucrats may manipulate the choices offered to voters in such a way as to lead to greater expenditure than the median of the most preferred amounts of voters. Shapiro and Sonstelie (1982) found evidence to support the hypothesis of bureaucratic manipulation. Stiglitz (1983) argued that renters' incentives in elections are inconsistent with efficiency. Courant, Gramlich and Rubinfeld (1979) suggested that public employee market power might also lead to inefficient levels of public provision. 
Our test is designed to detect undersupply of the kind described by Barlow or oversupply due to bureaucratic manipulation. Since we deal with consumers' reported preferences about expenditures in their own cities, we will not be able to detect undersupply or oversupply that occurs because people do not know what is good for them. We will also be unable to discover whether there is undersupply because of unrewarded spillovers from one city to another. Furthermore, our results can tell us nothing about whether efficiency would require a different assignment of people to cities. A test of the type we suggest can at best only determine whether the existing population of a city could make a Pareto improvement for its members by increasing or decreasing its public expenditures.

\section{Methodology}

Suppose that we observe a number of communities (school districts in our case) each of which supplies a local public good. Consumer $i$ who lives in community $j$ has a marginal rate of substitution between the public and private goods that is a function of the form:

$$
m_{i}=m\left(A_{j}, Y_{i}, H_{i}, Z_{j}\right)
$$

where $A_{j}$ is the amount of the public good provided in community $j, Y_{i}$ is $i$ 's disposable income (consumption of private goods), $H_{i}$ is a vector of personal characteristics of person $i$ (such as age, sex, family status, etc.) and $Z_{j}$ is a vector of characteristics of community $j$ (such as its population, climate, proximity to other cities, etc.).

To make a manageable task of estimating the sum of marginal rates of substitution, we will have to make some restrictive assumptions about the functional form of $m\left(A_{j}, Y_{i}, H_{i}, Z_{j}\right)$. In particular, we assume that individual marginal rate of substitution functions are of the form:

$$
\begin{aligned}
m\left(A_{j}, Y_{i}, H_{i}, Z_{j}\right)= & \beta_{0}+\beta_{1} \ln A_{j}+\beta_{2} \ln Y_{i}+\sum_{k} \beta_{3 k} \ln Z_{j \mathrm{k}} \\
& +\sum_{k} \beta_{4 k} H_{i k}+\varepsilon_{i} .
\end{aligned}
$$

Let $X_{i}$ denote the column vector $\left(1, \ln A_{j}, \ln Y_{i}, \ln Z_{j}, H_{i}\right)$ of right-hand variables of the MRS equation. Fq. (2) can then be written simply as:

$$
m_{i}=\beta^{\prime} X_{i}+\varepsilon_{i}
$$

We estimate the marginal rate of substitution function, $m\left(Y_{i}, A_{j}, H_{i}, Z_{j}\right)$, for 
expenditures on public primary and secondary education in Michigan using a 1978 survey of Michigan households [see Courant, Gramlich and Rubinfeld (1979)]. Once we have estimates of this function, based on this statewide sample, we can try to predict the sum of marginal rates of substitution in individual school districts. We can then compare this sum with the marginal cost of public goods to the school district. If we find that the predicted sum of marginal rates of substitution in this school district is greater than our estimate of the marginal cost of schooling to the district, it may be that the district is spending too little on public goods from the standpoint of efficiency. It might also be the school district is different in some way that we have not measured from other districts in the state. But if there is a systematic tendency to undersupply (oversupply) local public education, then when we compare the predicted sums of marginal rates of substitution to marginal costs for a large number of school districts we should expect to find that the predicted sums of marginal rates of substitution on average tend to exceed (fall short of) the estimated marginal costs of public goods.

From the Courant, Gramlich and Rubinfeld survey, we can calculate respondent $i$ 's tax price, $t_{i}$. If her home community provided the same amount that she would choose given her tax price, then each respondent's tax price would be equal to her marginal rate of substitution, so that $m_{i}=t_{i}$. We could then estimate the parameters of the marginal rate of substitution function simply be running a regression in which the dependent variable is the tax price, $t_{i}$.

While people may tend to move to communities where the provision of public goods is in accordance with their tastes, there is no reason to expect unanimous agreement within communities about expenditure levels. It is true that if people sorted themselves so that residents of the same community had nearly identical tastes and incomes, then with an equitable tax structure and a reasonably responsive government, we would expect all residents to be getting approximately the amount of public goods that they would choose for themselves given the tax structure. But there are strong economic forces that lead to diversity within communities. People with different occupational skills find it advantageous to work together and to live in close proximity. The housing stock may be highly variable in age, quality, size of units, and attractiveness of location. It is not surprising therefore that within communities there is a wide range in the incomes, education levels, ages, and family sizes of residents. While taxes of different types of consumers could possibly be adjusted to achieve near unanimity about quantities, we cannot expect on a priori grounds that communities will be in Lindahl equilibrium. And indeed empirically there is no such near-unanimity. In the Courant, Gramlich and Rubinfeld survey about 25 percent of the respondents wanted higher and about 17 percent wanted lower expenditures on public goods than were currently supplied in their communities. 
The fact that community choice is voluntary leads to a potentially important statistical problem. This problem of 'Tiebout bias' [Goldstein and Pauly (1981)] can be described as follows. Define the variable $\eta_{i}$ to be the difference between household i's marginal rate of substitution and its tax price. Thus, we have:

$$
t_{i}=m\left(A_{j}, Y_{i}, H_{i}, Z_{j}\right)+\eta_{i}
$$

and therefore from (3) it follows that

$$
t_{i}=\beta^{\prime} X_{i}+\varepsilon_{i}+\eta_{i}
$$

If $\eta_{i}$ were uncorrelated with variables $X_{i}$, then the mismatch between $t_{i}$ and $m_{i}$ would cause no econometric problems. Then if $\varepsilon_{i}$ is also uncorrelated with $X_{i}$, unbiased estimators of the parameters of eq. (5) could be found by ordinary least squares. (One instance where this would be the case is where $\eta_{i}$ is zero for all $i$.) We want to take account of the possibility that $\eta_{i}$ is correlated with the right-hand-side variables, $X_{i}$. For this reason we will have to use a more elaborate econometric method which is described in the remainder of this section.

We focus on a survey question in which respondents were asked whether they would prefer school spending to increase, decrease or remain the same, if they knew that their taxes would change to reflect these expenditure changes. Because the responses take the form of discrete rather than continuous variables, we must use a qualitative response model. We postulate that people only say that they are dissatisfied with the current state of affairs if their tax price is sufficiently different from their marginal rate of substitution. If the difference is not sufficiently large, they respond that they want local school expenditures to remain the same $(S)$. If their marginal rate of substitution is sufficiently larger than their tax price, they respond that they want more expenditures $(M)$ and if it is sufficiently smaller they respond that they want less $(L)$. The concept of sufficient difference is formalized by a parameter $\delta$ such that the response is $(M)$ if $m_{i}>t_{i}+\delta$; $(L)$ if $m_{i}<t_{i}-\delta$; and (S) if $t_{i}-\delta<m_{i}<t_{i}+\delta$.

Recalling eq. (3), we see that the probabilities of individual $i$ 's responses conditional on a tax rate $t_{i}$ and vector of characteristics $X_{i}$ are:

$$
\begin{aligned}
& P\left(M_{i} \mid t_{i}, X_{i}\right)=P\left(\varepsilon_{i}>t_{i}-\beta^{\prime} X+\delta\right), \\
& P\left(L_{i} \mid t_{i}, X_{i}\right)=P\left(\varepsilon_{i}<t_{i}-\beta^{\prime} X-\delta\right), \\
& P\left(S_{i} \mid t_{i}, X_{i}\right)=P\left(t_{i}-\beta^{\prime} X-\delta \leqq \varepsilon_{i} \leqq t_{i}-\beta^{\prime} X+\delta\right) .
\end{aligned}
$$


Assuming that $\varepsilon$ has a standard normal distribution, the probabilities can be expressed in terms of the standard normal cumulative distribution as follows:

$$
\begin{gathered}
P\left(M_{i} \mid t_{i}, X_{i}\right)=1-F\left(\frac{t_{i}-\beta^{\prime} X+\delta-E\left(\varepsilon \mid t_{i}, X_{i}\right)}{\sigma\left(\varepsilon \mid t_{i}, X_{i}\right)}\right), \\
P\left(L_{i} \mid t_{i}, X_{i}\right)=F\left(\frac{t_{i}-\beta^{\prime} X-\delta-E\left(\varepsilon \mid t_{i}, X_{i}\right)}{\sigma\left(\varepsilon \mid t_{i}, X_{i}\right)}\right), \\
P\left(S_{i} \mid t_{i}, X_{i}\right)=F\left(\frac{t_{i}-\beta^{\prime} X+\delta-E\left(\varepsilon \mid t_{i}, X_{i}\right)}{\sigma\left(\varepsilon \mid t_{i}, X_{i}\right)}\right) \\
-F\left(\frac{t_{i}-\beta^{\prime} X-\delta-E\left(\varepsilon \mid t_{i}, X_{i}\right)}{\sigma\left(\varepsilon \mid t_{i}, X_{i}\right)}\right) .
\end{gathered}
$$

If $\varepsilon$ were distributed independently of $\left(t_{i}, X_{i}\right)$, it would be the case that $E\left(\varepsilon \mid t_{i}, X_{i}\right)=0$ and standard, ordered probit estimation would yield consistent and efficient estimators of the parameters $\beta$ and $\delta$. But we suspect that this is not the case. As we argued in connection with eq. (5), even if we are willing to assume that $\varepsilon_{i}$ is uncorrelated with $X_{i}$ by itself, the correlation between $\varepsilon_{i}$ and $t_{i}$ conditional on $X_{i}$ will generally be nonzero. Similarly, since the vector $X_{i}$ includes as one of its components actual school spending levels in $i$ 's community $\left(\ln A_{j}\right)$, the correlation between $\varepsilon_{i}$ and $X_{i}$ given $t_{i}$ is likely to be nonzero. Failure to recognize these possible correlations can result in what we call Tiebout bias, or bias that occurs because people take into account their preferences for public goods when they decide where to live.

To deal with possible correlation between $\varepsilon$ and $\left(t_{i}, X_{i}\right)$, we introduce a set of instrumental variables which plausibly have a negligible influence on the marginal rate of substitution functions but which may affect either $t_{i}$ or $\boldsymbol{A}_{j}$. In the next section we will describe these instrumental variables, which are denoted by the vector $W_{i}$. Let us define $\tilde{X}_{i}$ to be the vector obtained by dropping the component $\ln A_{j}$ from the vector $X_{i}$. Our approach is to add two equations to the model, which may themselves be simultaneously determined. The reduced forms are follows:

$$
\begin{aligned}
& t_{i}=\theta_{11} \tilde{X}_{i}+\theta_{12} W_{i}+\omega_{1 i}, \\
& \ln A_{j}=0_{21} \tilde{X}_{i}+0_{22} W_{i}+\omega_{2 i},
\end{aligned}
$$

where $\omega_{1}$ and $\omega_{2}$ are random errors assumed to be uncorrelated with $W$ and $\tilde{X}$. We estimate the system of eqs. (7)-(9), using the method of full information maximum likelihood. The relevant likelihood function is des- 
cribed in the appendix. A detailed discussion of the approach can be found in Rubinfeld, Shapiro and Roberts (1987).

\section{Predicting individual marginal rates of substitution}

Our source of data is a sample of 1093 Michigan homeowners from a survey of Michigan voters residing in many different school districts. The fact that the sample includes voters from different school districts is important since we want to estimate the effects of characteristics of the school districts in which a respondent lives as well as the respondent's own characteristics on her willingness to pay for an additional unit of local public education. The individual characteristics of the respondents were recorded in the survey. The characteristics of the school systems were obtained from the Michigan Department of Education, while other community characteristics were taken from the 1970 U.S. Census First Count and Fourth Count School District data tapes. The definitions of all variables used in the estimation procedure are given in table 1.

\subsection{Measurement of independent variables for the prediction equations}

The way in which we measure quantity and price variables requires some discussion. The quantity of local public education that a respondent exper-

Table 1

Definition of variables.

\begin{tabular}{ll}
\hline PRICE & Individual's tax price \\
INA & Log of actual per pupil educational expenditure \\
LNY & Log of household disposable income \\
$R A C E$ & Dummy variables: 1 if black 0 otherwise \\
K05 & Number of children younger than six years old \\
K611 & Number of children between 6 and 11 \\
PRIVATE & Dummy variable: 1 if child in private school 0 otherwise \\
COLGRAD & Dummy variable: 1 if a college graduate 0 otherwise \\
NOTHS & Dummy variable: 1 if did not graduate from high school 0 otherwise \\
FEMALE & Dummy variable: 1 if female 0 otherwise \\
RTR/DI & Dummy variable: 1 if retired or disabled 0 otherwise \\
AGE65+ & Dummy variable: 1 if age over 650 otherwise \\
UNEMPLOY & Dummy variable: 1 if unemployed 0 otherwise \\
TRANSFER & Dummy variable: 1 if transfer payrnents received 0 other wise \\
LNPUPILS & Log of total school district enrollment \\
LNPUPS/B & Log of number of students per school \\
LNCTEACH & Log of county average teachers salary \\
LNCY & Log of county average income \\
LNCW & Log of county average wage rate \\
YDIST & Fraction of households with income within 30 percent of median (YDIST is \\
& thought of as a measure of population homogeneity) \\
$C C I T Y$ & Dummy variable: 1 if in central city 0 otherwise \\
SMSA & Dummy variable: 1 if in SMSA 0 otherwise
\end{tabular}


iences is measured by per student expenditures in the local school district. Per student expenditures by itself is the appropriate measure if there are constant returns to scale in the production of local education and if the costs of educational inputs are the same across districts. To allow for the possibility that there may be increasing or decreasing returns to scale, we included variables for total enrollment in the school district and average enrollment per school in the district. If there are increasing (decreasing) returns to scale, then providing an extra unit of education would be cheaper (more expensive) in larger school districts.

To allow for differences in costs due to differences in the wages paid to teachers, we included a variable measuring the average teachers' salary in the county where the school district was located. We used the average teachers' salary for the county in which the school district was located rather than the average teachers' salary in the district itself since differences in the latter might be strongly influenced by differences in the quality and experience of teachers while differences in the former might more closely reflect the market conditions facing the school district. Not only might the prices of school inputs differ from district to district, but so might the price of private goods. The average wage rate of nonteachers is used as a surrogate for a local price index for private goods. ${ }^{1}$ We also included as a variable the mean per capita income in the respondents' home county.

Since the commodity of interest is per student school expenditures, the tax price $t_{i}$ paid by family $i$ is the cost to $i$ of increasing the expenditure per student in the school district where the family resides by one dollar. In the survey, each respondent reported the assessed value of his home. The tax share of respondent $i$ was taken as the ratio of the assessed value of $i$ 's home to the total assessed value of property in i's home district. This tax share multiplied by the number of students in the district is the tax price, $t_{i}$.

We do not know much about the tax shares perceived by renters. Therefore we did not estimate separate marginal rate of substitution functions for renters. Instead, we assumed that renter preferences for public goods were the same as the preferences of homeowners (though of course their tax prices might be very different). When we later construct estimates of sums of marginal rates of substitution in the community, we must add in the estimated sum over renters as well as homeowners.

The respondent's disposable income was recorded from the survey. We included several other variables that describe individual characteristics which might influence demand. One variable of interest is whether a respondent has children in the local public schools. We included separate dummy variables for whether a respondent had children of school age and for whether a

\footnotetext{
${ }^{1}$ Differences in wages due simply to the occupational mix are excluded since we were able to find wages by occupation and compute a weighted average using the same weights for each occupation across communities.
} 
respondent had preschool children. We also include a variable for whether the respondent has children in private school. Other variables describe the respondent's race, sex, educational level, and whether the respondent is over 65 years of age, retired, unemployed, or receiving welfare payments.

We use four instrumental variables which could reasonably be expected to influence a taxpayer's actual tax price or the local school district's expenditure level but would not have a direct effect on willingnesses to pay for local public education. The first is the fraction of households in $i$ 's community with income within 30 percent of the community median income. The more homogeneous a population, the more agreement there should be about the correct level of spending. Furthermore, a person in a homogeneous community is not as likely as one in a heterogeneous community to have extremely high or low tax shares, since property values are likely to be more nearly equal. The second instrument is the percent change in educational expenditures between the fiscal year 1977-78 and 1978-79. Because moving is costly, households will often choose to remain in a community even though local spending changes at a different rate than household demand.

The third and fourth instruments are intended to measure the ease of 'voting with one's feet'. In urban areas there are many school districts within commuting distance of one's job. In an isolated community or a rural area there will typically be only one school district. If the workplace requires diversity of tastes and income, one would expect more sorting into communities of relatively homogeneous tastes and income in the suburbs than in isolated communities. We therefore include a dummy variable for whether a respondent resides in a central city and another dummy for whether the individual resides in an SMSA.

\subsection{The prediction equations for individuals}

We write the equation for predicting the marginal rate of substitution of individual $i$ as:

$$
\hat{m}_{i}=\hat{\beta}^{\prime} X_{i}+\hat{\varepsilon}_{i}\left(t_{i}, X_{i}, W_{i}\right),
$$

where $\hat{\varepsilon}_{i}\left(t_{i}, X_{i}, W_{i}\right)$ is the estimated value of $\varepsilon_{i}$ conditional on $t_{i}, X_{i}$ and $W_{i}$. As we show in the appendix, the expected value of the error term can be written:

$$
E\left(\varepsilon_{i} \mid t_{i}, X_{i}, W_{i}\right)=\gamma_{t} t_{i}+\gamma_{x}^{\prime} X_{i}+\gamma_{w}^{\prime} W_{i}
$$

Our estimating procedure provides us with unbiased estimators of the $\gamma$ 's so that

$$
\hat{\varepsilon}_{i}\left(t_{i}, X_{i}, W_{i}\right)=\hat{\gamma}_{t} t_{i}+\hat{\gamma}_{x}^{\prime} X_{i}+\hat{\gamma}_{w}^{\prime} W_{i}
$$


Eq. (10) is therefore equivalent to

$$
\hat{m}_{i}=\hat{\gamma}_{t} t_{i}+\left(\hat{\beta}^{\prime}+\hat{\gamma}_{x}^{\prime}\right) X_{i}+\hat{\gamma}_{w}^{\prime} W_{i} .
$$

The full information maximum likelihood estimates of the parameters of eq. (13) are given in table 2. Estimates of $\beta$ are in column 1 and estimates of $\gamma$ are in column 2 .

While the primary purpose of this effort is to provide prediction equations to be used for other purposes, it is of interest to notice the magnitudes of price and income elasticities that are implicit in the parameter estimates that we use. With convex preferences, we should expect the marginal rate of substitution between education and other goods to vary inversely with the amount of public education and directly with disposable income (since the latter measures expenditures on 'other goods'). As can be seen from table 2, the estimated effect of household income on marginal rate of substitution was significantly positive and the estimated effect of expenditure on marginal

Table 2

Maximum likelihood estimates - unconstrained.

\begin{tabular}{|c|c|c|c|c|c|}
\hline Variable & $\widehat{\beta}$ & $\hat{\gamma}$ & Variable & $\widehat{\hat{\beta}}$ & $\hat{\gamma}$ \\
\hline$\overline{C O N S T A N T}$ & $\begin{array}{c}-1.265 \\
(2.425)\end{array}$ & $\begin{array}{r}-0.670 \\
(2.513)\end{array}$ & UNEMPLOY & $\begin{array}{c}0.007 \\
(0.126)\end{array}$ & $\begin{array}{c}-0.058 \\
(0.117)\end{array}$ \\
\hline PRICE & & $\begin{array}{c}0.977 \\
(0.026)\end{array}$ & TRANSFER & $\begin{array}{c}-0.163 \\
(0.150)\end{array}$ & $\begin{array}{c}0.138 \\
(0.150)\end{array}$ \\
\hline$L N A$ & $\begin{array}{c}-0.738 \\
(0.482)\end{array}$ & $\begin{array}{c}0.723 \\
(0.497)\end{array}$ & LNPUPILS & $\begin{array}{c}-0.035 \\
(0.029)\end{array}$ & $\begin{array}{c}0.021 \\
(0.030)\end{array}$ \\
\hline$L N Y$ & $\begin{array}{c}0.171 \\
(0.027)\end{array}$ & $\begin{array}{c}-0.151 \\
(0.017)\end{array}$ & LNPUPS/B & $\begin{array}{c}0.229 \\
(0.090)\end{array}$ & $\begin{array}{c}-0.195 \\
(0.095)\end{array}$ \\
\hline$R A C E$ & $\begin{array}{c}0.212 \\
(0.193)\end{array}$ & $\begin{array}{r}-0.052 \\
(0.065)\end{array}$ & DETROIT & $\begin{array}{c}-0.218 \\
(0.117)\end{array}$ & $\begin{array}{c}0.230 \\
(0.121)\end{array}$ \\
\hline K05 & $\begin{array}{c}-0.013 \\
(0.042)\end{array}$ & $\begin{array}{c}0.042 \\
(0.027)\end{array}$ & LNCTEACH & $\begin{array}{c}0.532 \\
(0.520)\end{array}$ & $\begin{array}{r}-0.432 \\
(0.472)\end{array}$ \\
\hline$K 611$ & $\begin{array}{c}0.038 \\
(0.038)\end{array}$ & $\begin{array}{c}-0.017 \\
(0.025)\end{array}$ & $L N C Y$ & $\begin{array}{c}0.661 \\
(1.036)\end{array}$ & $\begin{array}{c}-0.842 \\
(1.130)\end{array}$ \\
\hline PRIVATE & $\begin{array}{c}0.003 \\
(0.084)\end{array}$ & $\begin{array}{c}-0.042 \\
(0.068)\end{array}$ & $L N C W$ & $\begin{array}{c}-0.727 \\
(1.345)\end{array}$ & $\begin{array}{c}1.010 \\
(1.464)\end{array}$ \\
\hline COLGRAD & $\begin{array}{c}0.130 \\
(0.046)\end{array}$ & $\begin{array}{c}-0.110 \\
(0.043)\end{array}$ & $S M S A$ & & $\begin{array}{c}-0.010 \\
(0.022)\end{array}$ \\
\hline NOTHS & $\begin{array}{c}-0.049 \\
(0.054)\end{array}$ & $\begin{array}{c}0.025 \\
(0.044)\end{array}$ & CCITY & & $\begin{array}{c}-0.013 \\
(0.026)\end{array}$ \\
\hline FEMALE & $\begin{array}{c}0.028 \\
(0.036)\end{array}$ & $\begin{array}{c}-0.008 \\
(0.031)\end{array}$ & $P C E X P$ & & $\begin{array}{c}-0.361 \\
(0.431)\end{array}$ \\
\hline$R T R / D I$ & $\begin{array}{c}-0.008 \\
(0.097)\end{array}$ & $\begin{array}{c}-0.061 \\
(0.060)\end{array}$ & YDIST & & $\begin{array}{c}-0.226 \\
(0.220)\end{array}$ \\
\hline$A G E 65+$ & $\begin{array}{c}0.021 \\
(0.074)\end{array}$ & $\begin{array}{c}0.000 \\
(0.065)\end{array}$ & & & \\
\hline
\end{tabular}

- Log likelihood: 727.47 .

Note: Standard errors are in parentheses. 
rate of substitution was significantly negative. The implied income elasticity of demand based on these estimates is 0.23 . The implied price elasticity of demand is -0.87 .2$

The reader is free to explore and interpret other coefficients that appear in the table. The estimates of $\gamma_{t}$ and $\gamma_{A}$ (where $\gamma_{A}$ is the element in the vector $\gamma_{X}$ that is associated with $\ln A$ ) tell us about the correlation between $\varepsilon$ and $(t, X)$, which is to say, the importance of Tiebout sorting. As we demonstrate in the appendix, if there were no correlation between $\varepsilon$ and $(t, X)$, then $\gamma_{t}$ and $\gamma_{A}$ would both be zero. We find, using asymptotic $t$-tests, that $\gamma_{t}$ (but not $\gamma_{A}$ ) is significantly different from zero at the 1 percent level.

In table 3 we present the maximum likelihood estimates of the marginal rate of substitution function where no correction for Tiebout sorting is made. These estimates constrain $\varepsilon$ to be uncorrelated with $\omega_{1}$ and $\omega_{2}$, the unobserved determinants of tax price and actual expenditures (that is, $\gamma_{t}$ and $\gamma_{A}$ are constrained to zero). Almost all the coefficients of the constrained model are substantially larger than those of the general model. The

Table 3

Maximum likelihood estimates $-\gamma=0$.

\begin{tabular}{lrr}
\hline Variable & \multicolumn{1}{c}{$\hat{\beta}$} & $\begin{array}{l}\text { Standard } \\
\text { error }\end{array}$ \\
\hline CONSTANT & -42.382 & 32.337 \\
LNA & -1.448 & 1.686 \\
LNY & 0.791 & 0.507 \\
RACE & 6.823 & 3.545 \\
K05 & 1.217 & 0.688 \\
K611 & 0.861 & 0.539 \\
PRIVATE & -1.686 & 1.189 \\
COLGRAD & 0.863 & 0.713 \\
NOTHS & -1.027 & 0.752 \\
FEMALE & 0.754 & 0.571 \\
RTR/DI & -2.863 & 1.632 \\
AGE65 + & 0.885 & 0.981 \\
UNEMPLOY & -2.139 & 1.714 \\
TRANSFER & -1.026 & 1.561 \\
LNPUPILS & -0.588 & 0.421 \\
LNPUPS/B & 1.237 & 0.918 \\
DETROIT & 0.297 & 1.303 \\
LNCTEACH & 1.780 & 3.749 \\
LNCY & -7.247 & 5.881 \\
LNCW & 10.081 & 7.509 \\
\hline
\end{tabular}

-Log likelihood: 731.51 .

\footnotetext{
${ }^{2}$ These estimates are obtained by solving the equation $m=\beta_{1} \ln A+\beta_{2} \ln Y+$ constants for $\ln A$ as a function of the other variables. When a consumer is getting the desired amount of public goods, $m$ is equal to the price $p$ that he pays for them. Then we have $\ln A=$ $\left(p-\beta_{2} \ln Y+\right.$ constants) $/ \beta_{1}$. The income elasticity is therefore just $-\beta_{2} / \beta_{1}$ and the price elasticity evaluated at the mean price is just $\bar{p} / \beta_{1}$. Using our estimates $\beta_{1}$ and $\beta_{2}$, we find 0.23 and -0.87 , respectively.
} 
likelihood ratio test between the constrained and unconstrained models yields a chi-square ( 2 d.f.) of 8.10 . As a result, the hypothesis of zero covariance, or the exogeneity of both expenditures and tax price, can be rejected at the 1 percent level.

\section{Testing for efficiency of community expenditures}

\subsection{Predicting community sums of marginal rates of substitution}

Now that we have prediction equations for individual marginal rates of substitution, we can use these equations, together with information available from the Census about the distributions of economic and demographic characteristics in school districts, to predict the sum of marginal rates of substitution in any school district in Michigan. The way we proceed is as follows. Let $S_{j}$ be the set of households in community $j$ and let $m^{j}=\sum_{i \in S_{j}} m_{i}$. Since eq. (13) in linear in $t, X$, and $W$, we can estimate the sum of marginal rates of substitution as follows:

$$
\hat{m}^{j}=\sum_{i \in S_{j}} \hat{m}_{i}=\hat{\gamma}_{t} t^{j}+\left(\hat{\beta}^{\prime}+\hat{\gamma}_{x}^{\prime}\right) X^{j}+\hat{\gamma}_{w}^{\prime} W^{j},
$$

where $t^{j}=\sum_{i \in S_{j}} t_{i}, X^{j}=\sum_{i \in S_{j}} X_{i}$, and $W^{j}=\sum_{i \in S_{j}} W_{i}$.

If we sum the expression in eq. (3) over all consumers in community $j$, we have:

$$
m^{j}=\sum_{i \in S_{j}} m_{i}=\beta^{\prime} X^{j}+\varepsilon^{j},
$$

where $\varepsilon^{j}=\sum_{i \in S_{j}} \varepsilon_{i}$. From adding the expressions in eq. (11), it follows that:

$$
E\left(\varepsilon^{j} \mid t^{j}, X^{j}, W^{j}\right)=\gamma_{t} t^{j}+\gamma_{x}^{\prime} X^{j}+\gamma_{w}^{\prime} W^{j} .
$$

From eqs. (14), (15), and (16) it follows that:

$$
\begin{aligned}
\hat{m}^{j}-m^{j}= & \left(\hat{\beta}^{\prime}-\beta^{\prime}+\hat{\gamma}_{x}^{\prime}-\gamma_{x}^{\prime}\right) X^{j}+\left(\hat{\gamma}_{t}-\gamma_{t}\right) t^{j}+\left(\hat{\gamma}_{w}^{\prime}-\gamma_{w}^{\prime}\right) W^{j}-\varepsilon^{j} \\
& +E\left(\varepsilon^{j} \mid t^{j}, X^{j}, W^{j}\right) .
\end{aligned}
$$

For each community, we must find the aggregate vectors, $X^{j}$ and $W^{j}$. Most of the components of these vectors are aggregates that are readily available in statistics published by the U.S. Census or the Michigan Department of Education. For example, the Census records the number of households in each commmunity, the number of persons over 65 years of age, and the number of persons with a college education. 
Calculating the sum of $\ln Y$ in each community is slightly more difficult. Here the problem is twofold: the Census reports information on income rather than log of income, and the form of the information differs between families and unrelated individuals. The approach we have taken is to estimate the mean of $\ln Y$ for families from the information available on family income and the mean of $\ln Y$ for individuals from the information on individual income. Weighting these by the number of families and the number of unrelated individuals, respectively, we obtain the district-wide mean of $\ln Y$. The distribution of families in a school district was given for fifteen income brackets, allowing us to estimate the median family income (we assume a uniform distribution within each bracket). Then assuming income is distributed log-normally, we have, for families:

$$
\text { mean }(\ln Y)=\operatorname{median}(\ln Y)=\ln \operatorname{median}(Y) .
$$

For unrelated individuals, the only data available were aggregate income and the number of individuals. For them we took $\ln$ mean $(Y)$ as an approximation for mean $(\ln Y)$.

\subsection{Efficiency in the interest of society as a whole}

Let $c_{j}$ be the marginal cost of providing the local public good to community $j$. Then the Samuelson efficiency condition for community $j$ is expressed by the equation:

$$
c_{j}=m^{j}=\sum_{i \in S_{j}} m_{i}=\beta^{\prime} X^{j}+\varepsilon^{j} .
$$

In our application the public good is per student expenditures in the local public schools. The cost to a school district of increasing expenditures per student by one dollar is equal to the number of students in the district. Therefore $c_{j}$ is just the number of students enrolled in school district $j$. If the only benefits from local schools accrue to people living in the school district, and if district $j$ spends the efficient amount, then we should have $m^{j} / c_{j}=1$. For the 497 Michigan school districts, the average ratio of $\hat{m}^{j}$ to $c_{j}$ is 0.748 . The distribution of the computed values of the ratio of community MRS to marginal cost is shown in fig. 1 . More than 80 percent of the school districts have $\hat{m}^{j} / c_{j}<1$.

It is possible to use our estimates to identify school districts for which there is an especially large divergence between the sum of marginal rates of substitution and marginal cost. But it is important to remember that for a particular community, such a divergence is not necessarily an indication of inefficiency. It might be that unobserved differences in tastes for education or 


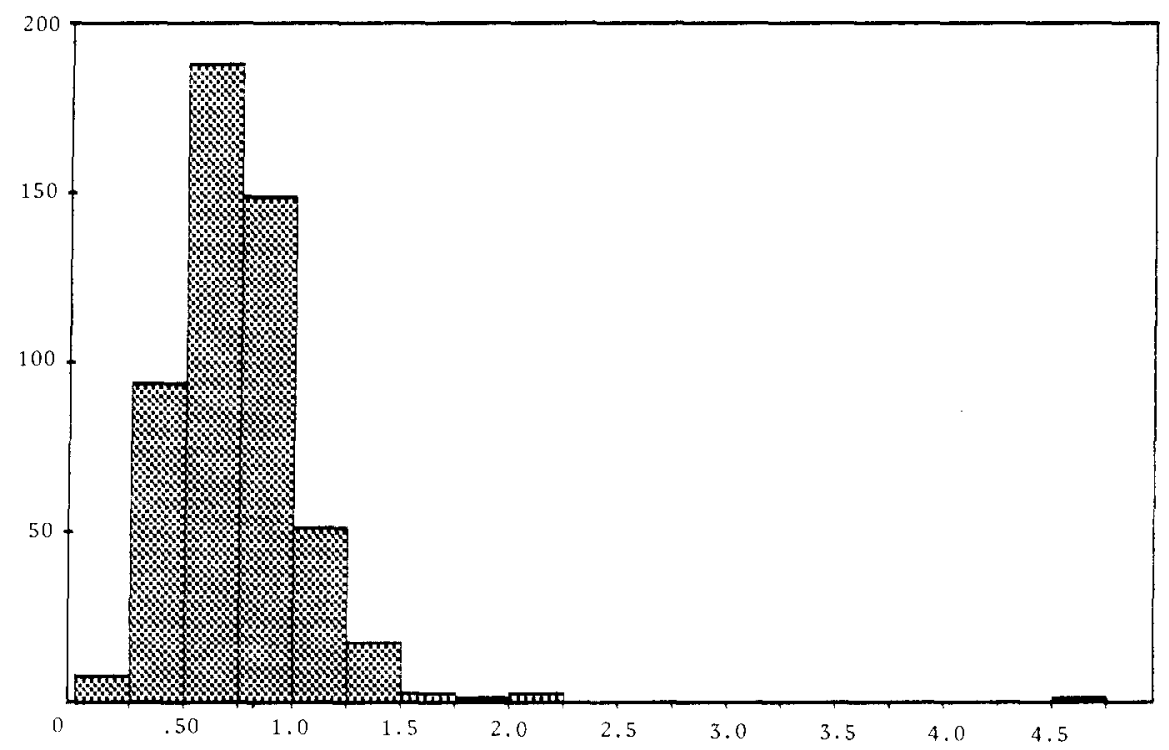

Fig. 1. Community marginal rates of substitution.

unobserved cost differences account for the discrepancy. In our notation, this would mean that $\varepsilon^{j}$ differs from its expected value.

Although $\varepsilon^{j}-E\left(\varepsilon^{j} \mid t^{j}, X^{j}, W^{j}\right)$ will vary across individual districts, we can expect that the average value of this difference over the 497 school districts in Michigan will be very close to zero. To test for a systematic tendency for overspending or underspending in Michigan, we therefore want to study the average over all Michigan school districts of the ratio $\hat{m}^{j} / c_{j}$. Under the null hypothesis that there is no systematic bias toward overspending or underspending, we would have $(1 / n) \sum_{j=1}^{n}\left(m^{j} / c_{j}\right)=1$. From eq. (17) it follows that:

$$
\frac{1}{n} \sum_{j=1}^{n} \frac{\hat{m}^{j}}{c_{j}}-1=\left(\hat{\beta}^{\prime}-\beta^{\prime}+\hat{\gamma}_{x}^{\prime}-\gamma_{x}^{\prime}\right) \bar{X}+\left(\hat{\gamma}_{t}-\gamma_{t}\right) \bar{t}+\left(\hat{\gamma}_{w}^{\prime}-\hat{\gamma}_{w}\right) \bar{W}-\bar{\varepsilon}
$$

where

$$
\bar{X}=\frac{1}{n} \sum_{j=1}^{n} \frac{X^{j}}{c_{j}}, \quad \bar{t}=\frac{1}{n} \sum_{j=1}^{n} \frac{t^{j}}{c_{j}}, \quad \bar{W}=\frac{1}{n} \sum_{j=1}^{n} \frac{W^{j}}{c_{j}}
$$

and

$$
\bar{\varepsilon}=\frac{1}{n} \sum_{j} \frac{\varepsilon^{j}-E\left(\varepsilon^{j} \mid t^{j}, X^{j}, W^{j}\right)}{c_{j}}
$$

The variance of the expression in eq. (19) comes from two sources. One 
source is the variance of the $\hat{\beta}$ 's and $\hat{\gamma}$ 's around the 'true' $\beta$ 's and $\gamma$ 's. The second source of variance is the random variable $\bar{\varepsilon}$. Since $\bar{\varepsilon}$ is a mean of statistically independent community specific random variables taken from 497 communities, the latter source of variance can reasonably be neglected. As we see from eq. (19), the difference $(1 / n) \sum_{j=1}^{n}\left(\hat{m}^{j} / c_{j}\right)-1$ is a linear combination of the difference between our parameter estimates for the $\beta$ 's and $\gamma$ 's and their expected value. Since we have estimates of the variancecovariance matrix for these estimates, we can readily calculate an estimate of the standard deviation of the expression in eq. (19). According to our computations, the random variable $(1 / n) \sum_{j=1}^{n}\left(\hat{m}^{j} / c_{j}\right)$ takes the value 0.748 and the estimated standard error of this random variable is 0.09 . Therefore we must reject the hypothesis of efficiency at the 5 percent significance level.

These results suggest that the sum of marginal rates of substitution between local public education and other goods in Michigan communities tends to be less than the marginal cost of public goods. If the only beneficiaries of local public education are the residents of the community in which the education is provided, this would mean that most communities spend too much on local public education from the standpoint of social efficiency.

\subsection{Efficiency in the interest of the localities}

There is another way in which the efficiency of local governments could be measured. Instead of comparing the sum of marginal rates of substitution with the marginal cost of local public education, we might compare this sum with the fraction of marginal costs that are borne by the voters in the school district. This would give us a test of whether school districts are acting efficiently in the interest of their own residents.

In Michigan, at the time of this survey, marginal increments to local revenue came from the local property tax. In most school districts a large fraction of the property tax base is nonresidential property and, of course, much of this property is either not locally owned or concentrated in the hands of a very small number of voters. (For the included communities nonresidential property is 35 percent of the property tax base.) If people believe that taxes assessed on nonresidential property are fully exported and if the fraction of the local property tax base that is residential property is $s^{j}$, then efficiency from a purely local point of view requires that $m^{j} / c_{j}=s^{j}$.

For 454 of the 497 communities that we observed, $\hat{m}^{j} / c_{j}-s^{j}$ is positive and for the remaining communities $\hat{m}^{j} / c_{j}-s^{j}$ is negative. Under the null hypothesis that, on average, $m^{j} / c_{j}=s^{j}$, eq. (19) would be replaced by:

$$
\frac{1}{n} \sum_{j=1}^{n} \frac{\hat{m}^{j}}{c_{j}}-\bar{s}=\left(\hat{\beta}^{\prime}-\beta^{\prime}+\hat{\gamma}_{x}^{\prime}-\gamma_{x}^{\prime}\right) \bar{X}+\left(\hat{\gamma}_{t}-\gamma_{t}\right) \bar{t}+\left(\hat{\gamma}_{w}^{\prime}-\hat{\gamma}_{w}\right) \bar{W}+\bar{\varepsilon},
$$


where $\bar{s}=(1 / n) \sum_{j=1}^{n} s^{j}$.

As it turns out $\bar{s}=0.649$ and $(1 / n) \sum_{j=1}^{n}\left(\hat{m}^{j} / c_{j}\right)=0.748$. The estimated standard error of the random variable $(1 / n) \sum_{j=1}^{n}\left(\hat{m}^{j} / c_{j}\right)-\bar{s}$ is 0.09 . Therefore we are not able to reject the hypothesis that, on average, $m^{j} / c_{j}=s^{j}$.

\section{Concluding remarks}

This is, as far as we know, the first attempt in the literature to empirically test the Samuelson conditions for efficient provision of public goods. Accordingly, we urge the reader to interpret our results cautiously. Other data sources and other methods of approach may lead to very different conclusions. To illustrate this point, we must point out that our corrections for Tiebout bias had a very strong effect on our results. If we estimate the marginal rate of substitution functions, making no correction for Tiebout bias, but otherwise pursuing the same methods, we find that the average value of the ratio of summed marginal rates of substitution to marginal cost in Michigan school districts is 1.62 , while with the correction, the average value is 0.748 . Thus, the uncorrected estimates would suggest substantial underspending and the corrected estimates suggest a tendency toward overspending.

The choice of which variables to treat as endogenous also makes a difference, albeit a smaller difference, to the efficiency calculation. When the endogeneity correction is applied only to expenditures, and not to price, the average ratio of summed MRS to marginal cost is about 0.94 . However, when the endogeneity correction is applied to tax price alone, the resulting efficiency calculation is 0.80 , much closer to the result of applying the endogeneity correction to both variables.

These facts suggest that if someone wants to prove either that too much or too little is being spent, he can find the desired result by fiddling with the specification of the model. We think that the correction we have chosen is preferable on theoretical grounds to the uncorrected estimates. Other data sets and other choices of instrumental variables may lead to different conclusions. But if there is a strong tendency in one direction or another, we expect that it would be confirmed in repeated studies. We hope that others will try to investigate this question empirically.

With these qualifications in mind, suppose we take our empirical results as roughly correct, what conclusions could we draw? On average it appears that the sum of marginal rates of substitution for local public education is lower than marginal cost. If there are no spillovers of bencfits from one school district to others, this would mean that local school districts are overspending from the standpoint of social efficiency. But, on average, the sum of the residents' marginal rates of substitution is about equal to the share of the costs that are borne by local taxpayers. This means that local school districts 
tend to act quite efficiently in promoting the interests of the voting population which does not bear the entire cost of local education. Whether this is a socially efficient arrangement depends on the size of the externalities generated by local education for the rest of the economy.

So, even if our empirical results were unquestioned, we would not have ended the debate on whether too much or too little is being spent. Whether or not the expenditure level is efficient from the viewpoint of society as a whole it would be of considerable interest of our conclusion that local school districts tend to act efficiently in the interests of local voters is corroborated by other research.

\section{Appendix}

The system of eqs. (3), (8), and (9), in the text is assumed to have a vector of random disturbances $\left(\varepsilon, \omega_{1}, \omega_{2}\right)$ with a joint normal distribution with mean zero and with off-diagonal covariances that are not necessarily zero. It is the fact that these off-diagonal terms, $\sigma_{\omega_{1} \varepsilon}, \sigma_{\omega_{2} \varepsilon}$, and $\sigma_{\omega_{1} \omega_{2}}$ are nonzero that causes Tiebout bias to be a problem.

A full information maximum likelihood procedure is used to obtain consistent parameter estimates. Letting $R$ represent an individual's more/ same/less response, the likelihood function that is maximized represents the joint probability of observing the given set of $(R, t, \ln A)$ vectors. For example, given $X_{0}$ and $W_{0}$, the likelihood of observing a 'more' response, tax price $t_{0}$, and expenditure level, $A_{0}$ is:

$$
\operatorname{pr}\left(\text { more }, t_{0}, \ln A_{0}\right)=\int_{\left(t_{0}+\delta-\beta^{\prime} X_{0}\right) / \sigma_{\varepsilon}}^{\infty} f\left(\varepsilon, \omega_{10}, \omega_{20}\right) \mathrm{d} \varepsilon,
$$

where $\omega_{10}=t_{0}-\theta_{11} \tilde{X}_{0}-\theta_{12} W_{0}$ and $\omega_{20}=\ln A_{0}-\theta_{21} \tilde{X}_{0}-\theta_{22} W_{0}$. Using Bayes' law,

$$
f\left(\varepsilon, \omega_{1}, \omega_{2}\right)=f\left(\varepsilon \mid \omega_{1}, \omega_{2}\right) f\left(\omega_{1}, \omega_{2}\right)=f\left(\varepsilon \mid \omega_{1}, \omega_{2}\right) f\left(\omega_{1} \mid \omega_{2}\right) f\left(\omega_{2}\right) .
$$

And, from standard results for conditional distributions of multivariate normal variables, $E\left(\varepsilon \mid \omega_{10}, \omega_{20}\right)=\lambda_{1} \omega_{10}+\lambda_{2} \omega_{20}$ and $E\left(\omega_{1} \mid \omega_{20}\right)=\lambda_{3} \omega_{20}$, where

$$
\begin{aligned}
& \lambda_{1}=\frac{\sigma_{\omega_{1}}^{2} \sigma_{\varepsilon \omega_{1}}-\sigma_{\varepsilon \omega_{2}} \sigma_{\omega_{1} \omega_{2}}}{\sigma_{\omega_{1}}^{2} \sigma_{\omega_{2}}^{2}-\sigma_{\omega_{1} \omega_{2}}^{2}} \\
& \lambda_{2}=\frac{\sigma_{\omega_{1}}^{2} \sigma_{\varepsilon \omega_{2}}-\sigma_{\varepsilon \omega_{1}} \sigma_{\omega_{1} \omega_{2}}}{\sigma_{\omega_{1}}^{2} \sigma_{\omega_{2}}^{2}-\sigma_{\omega_{1} \omega_{2}}^{2}}
\end{aligned}
$$

and

$$
\lambda_{3}=\frac{\sigma_{\omega_{1} \omega_{2}}}{\sigma_{\omega_{2}}^{2}}
$$


Then the term in the likelihood function corresponding to this observation is:

$$
\begin{aligned}
& \ln \left(1-F\left(\frac{t_{0}-\beta^{\prime} X_{0}+\delta-\lambda_{1} \omega_{10}-\lambda_{2} \omega_{20}}{\sigma_{\varepsilon \mid \omega_{1}, \omega_{2}}}\right)\right)-\frac{1}{2}\left(\ln 2 \pi \sigma_{\omega_{1} \mid \omega_{2}}^{2}+\ln 2 \pi \sigma_{\omega_{2}}^{2}\right) \\
& -\frac{\left(\omega_{10}-\lambda_{2} \omega_{20}\right)^{2}}{2 \sigma_{\omega_{1} \mid \omega_{2}}^{2}}-\frac{\omega_{20}^{2}}{2 \sigma_{\omega_{2}}^{2}} .
\end{aligned}
$$

In a similar fashion, the likelihood function for the entire sample becomes:

$$
\begin{aligned}
L= & \sum_{i \in \text { Less }} \ln F\left(\frac{t_{i}-\beta^{\prime} X_{i}-\delta-\lambda_{1} \omega_{1 i}-\lambda_{2} \omega_{2 i}}{\sigma_{\varepsilon \mid \omega_{1}, \omega_{2}}}\right) \\
& +\sum_{i \in \text { Same }} \ln \left(F\left(\frac{t_{i}-\beta^{\prime} X_{i}+\delta-\lambda_{1} \omega_{1 i}-\lambda_{2} \omega_{2 i}}{\sigma_{\varepsilon \mid \omega_{1}, \omega_{2}}}\right)\right. \\
& \left.-F\left(\frac{\left.t_{i}-\beta^{\prime} X_{i}-\delta-\lambda_{1} \omega_{1 i}-\lambda_{2} \omega_{2 i}\right)}{\sigma_{\varepsilon \mid \omega_{1}, \omega_{2}}}\right)\right) \\
& +\sum_{i \in \operatorname{More}} \ln \left(1-F\left(\frac{t_{i}-\beta^{\prime} X_{i}+\delta-\lambda_{1} \omega_{1 i}-\lambda_{2} \omega_{2 i}}{\sigma_{\varepsilon \mid \omega_{1}, \omega_{2}}}\right)\right) \\
& -\frac{n}{2}\left(\ln 2 \pi \sigma_{\omega_{1} \mid \omega_{2}}^{2}+\ln 2 \pi \sigma_{\omega_{2}}^{2}\right)-\sum \frac{\left(\omega_{1 i}-\lambda_{3} \omega_{2 i}\right)^{2}}{2 \sigma_{\omega_{1} \mid \omega_{2}}^{2}}-\frac{\sum \omega_{2 i}^{2}}{2 \sigma_{\omega_{2}}^{2}} .
\end{aligned}
$$

Substituting $\omega_{1 i}=t_{i}-\theta_{11} \tilde{X}_{i}-\theta_{12} W_{i}$ and $\omega_{2 i}=\ln A_{i}-\theta_{21} \tilde{X}_{i}-\theta_{22} W_{i}$, we maximize this function with respect to $\beta, \delta, \theta, \lambda_{1}, \lambda_{2}, \lambda_{3}, \sigma_{\varepsilon \mid \omega_{1}, \omega_{2}}$, and $\sigma_{\omega_{1} \mid \omega_{2}}$.

We are concerned here, however, with predicting marginal rates of substitution, rather than with estimates of the structural model. That is, we are concerned with

$$
m=\beta^{\prime} X+\lambda_{1}\left(t-\theta_{11} \tilde{X}-\theta_{12} W\right)+\lambda_{2}\left(\ln A-\theta_{21} \tilde{X}-\theta_{22} W\right) .
$$

Gathering terms and making obvious substitutions, we can write:

$$
m=\beta^{\prime} X+\gamma_{t} t+\gamma_{x}^{\prime} X+\gamma_{w}^{\prime} W
$$

These are the reduced form parameter estimates $\beta$ and $\gamma$ that are reported in table 2. Notice that $\gamma_{t}=\lambda_{1}$ and $\gamma_{A}=\lambda_{2}$. We found $\hat{\delta}=0.128(0.129), \hat{\lambda}_{3}=$ $-0.026(0.009)$, and $\sigma_{\omega_{2}}=0.429(0.005)$. 


\section{References}

Barlow, Robin, 1970, Efficiency aspects of local school finance, Journal of Political Economy 78, $1028-1039$.

Bergstrom, Theodore, 1979, When does majority rule supply public goods efficiently?, Scandinavian Journal of Economics 8, 216-227.

Bergstrom, Theodore, Daniel Rubinfeld and Perry Shapiro, 1982, Micro-based estimates of demand functions for local school expenditures, Econometrica 50, 1183-1205.

Bewley, Truman, 1981, A critique of Tiebout's theory of local public expenditures, Econometrica 49, 713-737.

Bowen, Howard, 1943, The interpretation of voting in the allocation of economic resources, Quarterly Journal of Economics 58, 27-48.

Brazer, Harvey, 1961, Some fiscal implications of metropolitanism, in: Guthrie Birkhead, ed., Metropolitan issues: Social, governmental, fiscal (Maxwell Graduate School of Public Affairs, Syracuse University, Syracuse, New York).

Brennan, Geoffrey and James Buchanan, 1977, Toward a tax constitution for Leviathan, Journal of Public Economics 8, 255-273.

Brueckner, Jan, 1982, A test for allocative efficiency in the local public sector, Journal of Public Economics 19, 311-331.

Courant, Paul, Edward Gramlich and Daniel Rubinfeld, 1979, Public employee market power and the level of government spending, American Economic Review 69, 806-817.

Denzau, Arthur, Robert MacKay and Carolyn Weaver, 1981, On the initiative referendum option and the control of monopoly government, in: H.F. Ladd and T.N. Tideman, eds., Tax and expenditure limitation (Urban Institute, Washington, DC) 191-222.

Downs, Anthony, 1960, Why the government budget is too small in a democracy, World Politics $12,541-563$.

Galbraith, John Kenneth, 1958, The affluent society (Houghton-Miflin, Cambridge, MA).

Goldstein, Gerald and Mark Pauly, 1981, Tiebout bias on the demand for local public goods, Journal of Public Economics 16, 536-550.

Gramlich, Edward and Daniel Rubinfeld, 1982, Using micro data to estimate public spending demand functions and test the Tiebout and median voter hypothesis, Journal of Political Economy $90,535-560$.

Heckman, James, 1979, Sample selection bias as a specification error, Econometrica 47, 153-161.

Inman, Robert, 1982, Wages, pensions, and employment in the local public sector, in: Peter Mieszkowski aand George Peterson, eds., Public sector labor markets (Urban Institute, Washington, DC) $110-118$.

Ladd, Helen, 1975, Local education expenditures, fiscal capacity, and the composition of property tax base, National Tax Journal 28, 145-150.

Ledyard, John, 1983, The pure theory of large two candidate elections, Northwestern University Working paper.

Romer, Thomas and Howard Rosenthal, 1978, Political resource allocation, controlled agendas and the status quo, Public Choice 33, no. 4, 27-43.

Rubinfeld, Daniel, Perry Shapiro and Judith Roberts, 1987, Tiebout bias and the demand for public goods, Rcview of Economics and Statistics 69, no. 3, 426-437.

Samuelson, Paul, 1954, The pure theory of public expenditure, Review of Economics and Statistics 26, 387-398.

Shapiro, Perry and John Sonstelie, 1982, Did proposition 13 slay Leviathan?, American Economic Review 72, 184-190.

Stiglitz, Joseph, 1983, The theory of local public goods twenty-five years after Tiebout: A perspective, in: Jacques Thisse and H. Zoller, eds., Local provision of public services: The Tiebout model after twenty-five years (Academic Press, New York) 17-54.

Tiebout, Charles, 1956, A pure theory of local expenditures, Journal of Political Economy 64, 416-424.

Weisbrod, Burton, 1964, External benefits of public education: An economic analysis (Industrial Relations Section, Princeton University, Princeton, NJ).

Williams, Alan, 1966, The optimal provision of public goods in a system of local government, Journal of Political Economy 74, 10-33. 